\title{
Predicting the future of consumer panels
}

Received: 28th January, 2002

\begin{abstract}
Brian Wansink
is Professor of Marketing, Nutritional Science, and Agricultural and Consumer Economics at the University of Illinois at Urbana-Champaign. This paper is based on insights gathered by the author and the late Seymour Sudman during their writing of 'Consumer Panels', American Marketing Association (2002).
\end{abstract}

\section{Seymour Sudman (PhD University of Chicago 1962)}

was the Walter H. Stellner Distinguished Professor of Marketing at the University of Illinois from 1968 until his untimely death in 2000. Through a lifetime of active research, he contributed immeasurably to the area of survey design, sampling and methodology. He was actively involved in providing guidance to the U.S. Census Bureau, and he served as Deputy Director and Research Professor of the Survey Research Laboratory at the University of Illinois.

Abstract The future for consumer panels is rich. The data collection experience will be richer for consumers, and the data will be richer for researchers. The challenge will be in determining how to use this data to improve a manager's understanding of his or her consumers while avoiding concerns of commodification, research rationalization, and regulation. Following a discussion of these concerns, specific recommendations for consumer panel users and researchers are outlined.

'I think there is a world market for maybe five computers.' 1

There is an embarrassing danger in trying to predict the future. Yet the upside is often worth the embarrassment of inaccuracy. When trying to imagine what the future will bring, possibilities are brought into focus that could otherwise be lost.

The future for consumer panels is rich. The data collection experience will be richer for consumers, and the data will be richer for researchers. The challenge will be in determining how to use these data to improve a manager's understanding of his or her consumers. A mountain of data will not be difficult to collect. The difficulty lies in effectively mining that mountain for the gold it contains.

Technology will not only influence the way in which data are collected, but it will also influence the sociology of how panellists, researchers and managers respond to these data. The recommendations outlined in this paper are not so much intended to help control the future as much as to help be best prepared for the changes that might occur.

\section{PREDICTING THE FUTURE: RICHER EXPERIENCES AND RICHER DATA}

To believe consumer panels of the future will only be in the form of Web panels is probably no more accurate than someone in 1978 believing that music of the future would be in the form of 8 -track tapes. Consumer panels are now conducted in person, on the phone, through the mail and on the Web. The future of consumer panels may be shared with panel data that are collected on re-writeable compact disks, refrigerator panel displays, smart voice-activated appliances, video conference calls, personal displays or on 


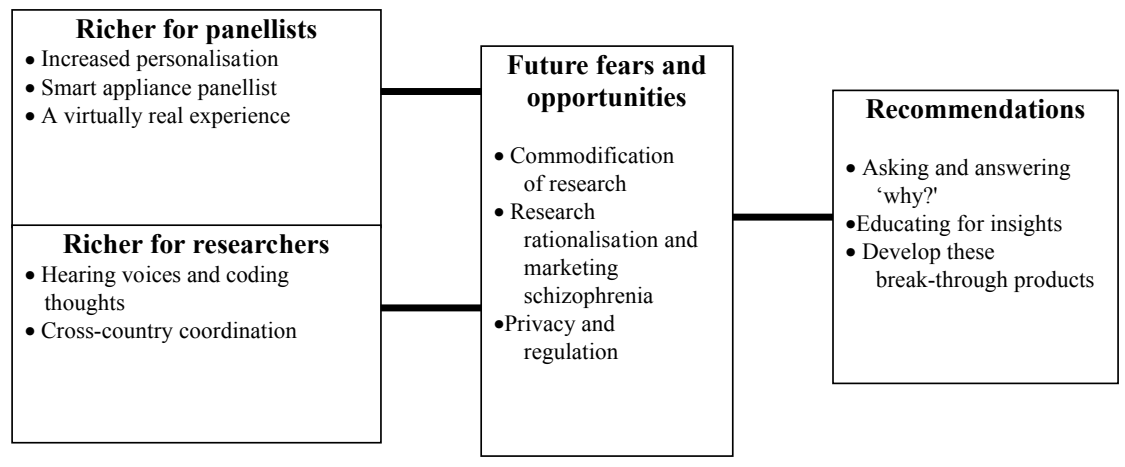

Figure 1: The future of consumer panels

high-resolution Web television. Figure 1 illustrates the future of consumer panels and the organisation of this paper.

\section{A richer experience for panellists}

\section{Increased personalisation}

Forthcoming waves of increased interactivity each carry the potential for increased personalisation. Just as panels have used fictitious representatives to give personality and a contact point to their company, so too can they use the pleasurable voice of the virtual hostess to welcome consumers and talk them through their panel experience. Not only can this virtual hostess provide explanations and clarifications, she can also reinforce a perceived degree of personalisation ('Thank you, for helping us, Naomi.').

Because of cross-referenced databases, fewer questions will need to be asked and others can be more confirmatory ('Do you still drive your white Jeep Cherokee?'). For some panellists, attrition occurs because they feel anonymous or unimportant. In a small way, this ability to 'reference and reinforce' will make the panel experience more personalised and more efficient. The objective is to reference those details that show familiarity with the panellist and reinforce the notion that a panellist's answers are important and that they are remembered. It may be a fine line, however, between a panellist believing that 'it's nice you remembered that about me' versus 'it's unnerving you remembered that'.

\section{Smart appliance panellists}

The command centre of a household is the kitchen, and it is likely to be one of the most promising frontiers for panel research. It is where people start the day, gather, take breaks, regroup and finish off with a midnight snack. With smart appliances, such as refrigerators with touch-screens and stovetops with microchips, there is an opportunity to use bar coding scanners to move beyond purchase behaviour and to collect more precise data on consumption and meal planning. Flat panel LCD touch-screens on refrigerators (which are also voice activated) allow consumers to keep track of their inventory by scanning products, and they allow consumers to make lists, order groceries online, send e-mails, check recipes, get cooking advice and programme and watch television. Just as in-store scanners enhanced understanding of shopping behaviour, smart appliances will enhance understanding of consumption behaviour.

The initial benefits of smart appliances are in how they enable consumers to maintain better inventory control, and 
how they help with meal preparation. Using the scanner, a wired refrigerator can provide researchers with unobtrusive measures of what is being consumed and when it is being consumed. Furthermore, because smart appliances can provide advice to consumers on their screens, it provides some idea of what recipes a person considers and when they make a meal choice based on a theme (Italian) versus when they make it by building a meal around a key ingredient (thawed ground beef). As inventory is depleted, automatic shopping lists will suggest repurchases that need to be made. When combined with purchase data that are collected from either the store or from inventory check-ins after returning from the store, questions can be answered about why and when purchase rates lag so far behind consumption or 'use up' rates for many products.

In networking smart appliances together, there is a tremendous potential for observing cooperating panellists. For instance, the same surveillance camera system that allows a mother in a kitchen to monitor her sleeping baby in an upstairs bedroom can also record how she is preparing food and the order in which meal preparation decisions are made. With the refrigerator serving as a cortex, it will not be long before it becomes networked with smart telephones, ovens, toasters, televisions, garbage cans and heating and air conditioning units.

\section{A virtually real experience}

The panel experience will move from pictures and sound, to slides, full-screen video and product dimensionality. Furthermore, while Web television and computer monitors are limited to two dimensions, advances in holography and a variety of innovative peripherals could alleviate even this constraint. Consider an experiential walk-around that involves interacting with a product, not unlike that seen in an interactive first-person experience with Playstations and other simulated reality games. With discontinuous access panels, consumption, attitudes and intentions can be vividly collected for existing products, new product introductions and new package concepts.

The power of simulation will provide a greater degree of specificity to the Web. No longer will questions be general, ${ }^{2}$ but questions will be asked of the panellists in a vivid, situationally-specific manner. The experience can be varied for people based on key segmentation variables, such as their age, or the age and genders of their children, and so forth. Their experiences can also be varied systematically to provide modal tests, such as $2 \times 2$ experimental designs that vary consumption-related scenarios in four systematic ways and then compare the different responses in each of the four conditions.

\section{Richer data for panel researchers}

\section{Hearing voices and coding thoughts}

One historical drawback of panel data is that they were not effective in providing qualitative explanations of behaviour. Most conventional questionnaires do not allow the space, and time and cost considerations to collect these data or to code and interpret them. The integration of two technological advances will solve this problem.

First, voice-activated surveys free panellists from having to write or type their responses. This, in turn, saves them time and effort and allows for more questions to be asked. This voice recognition software allows consumers to complement or supplement their quantitative responses with qualitative verbal information. They can then explain 
the process they went through when deciding on a purchase or when making a trade-off. Furthermore, voice recognition software will allow panellists to describe the thoughts and feelings they had when using a product, seeing an advert, tasting a product or comparing package designs. ${ }^{3}$ This information can help determine causality and generate insights.

These verbal protocols will be worth nothing, however, if they are not organised in a systematic way that enables analysis. Fortunately, advances in new generations of qualitative software will continue to help transform these data into a usable systematic form. This software can be used to code data in a number of ways. For instance, when capturing a person's thoughts and feelings toward using a particular product, each statement can be categorised as to whether it is a positive or negative comment, and on whether it is a general evaluative statement or a more attribute-specific statement. The exact nature of each statement can then be subcategorised based on the attributes they reflect.

\section{Cross-country coordination}

'Smart databases' will facilitate a researcher's ability to develop a global perspective. These automated databases will be able to search out a stratified or diversified panel, including one consisting of members from many different countries, for each survey.

The databases will be supported by an increase in the availability of instantaneous language translation programs that allow an unprecedented opportunity for cross-country comparisons. When there is a desire to make comparisons across languages, translation software will make near instantaneous conversions of a panel survey into other languages. This software will offer backward translation to double check meaning (eg from English to
Mandarin back to English). Furthermore, the same voice recognition software that enables qualitative responses to be given will also allow words to be translated and coded into whatever language is desired.

These advances will more quickly bring global markets together into one heterogeneous, but coordinated market. Understanding of the diversity of these different groups will increase, and the ability to provide recommendations and to understand why they differ will help companies better satisfy them while also enabling them to keep their identity. In this way, the global potential for certain products can be assessed early in their development. Changes can then be made to the product that make it most promising for a world market, or which makes it customisable by different panellists in different markets.

\section{FUTURE FEARS AND OPPORTUNITIES}

Science fiction movies and books are replete with the theme of technology outpacing man's ability to control it. The future brings the ability to collect more and better data and to make the panel experience richer and more satisfying for the consumer. It is less clear if marketers will know what to do with these data once they have them.

One concern is that the focus on cost and speed will lead to the death of answering 'why?' When a person is not trained to get behind the numbers, the marginal benefit of sophisticated data will not commensurately add to his or her ability to make more insightful decisions. Perhaps the core of the problem is in how graduate students are trained, particularly the MBAs who use panel results in positions as brand managers. MBAs are trained to see the 'big picture' and to develop vision. This often subjugates technical skills in favour of strategic 
thinking and team management. Yet at some point, it is insights about consumers that comprise the mosaic behind the big picture of successful companies. Learning how to run regressions, ANOVAs and chi-square tests can be reasonably easily taught. The value in doing so, however, is in being able to ask the next level of question that moves from numbers in a table to insights. Is the purpose of research merely to describe the data, or to tell a story? Is it to 'tag and bag', or is it to solve a mystery? Marketers do the former, not the latter.

\section{The commodification of research}

Research costs have been dropping faster as the use of the Web and standardised procedures reduce the time and labour necessary to execute a study. Yet, the same aspects that make online panel research so efficient also make it prone to commodification. When the positioning statement of an online panel company is 'we're faster and cheaper', that will unfortunately be the yardstick they will also be evaluated on as other online competitors emerge. Higher speed, lower costs and lower margins will have a predictable impact on quality. As one sign in a computer consultant's office reads 'cheap, fast and good: pick two'.

If the incremental value of a panel researcher is not made clear by that researcher, clients might overweight cost and speed. That is, a client might find themselves price shopping for eight cross-tabs he or she wants on a specified population of a prescribed size. Having articulated this, it is now time to find the lowest bidder.

Such technology will commodify the panel research industry. No longer will there be a premium on being a firm which goes beyond the numbers and provides insights or explanations that move understanding of consumers to another level. To a low bidder, there is no time for thoughtful analyses. The costly hiring of people who are talented and clever enough to generate these insights will be foregone in favour of a less expensive technician who can click a 'cross-tabs' button. This will drive out much of the diversity in the marketing research area in favour of large, low-cost suppliers.

Low-cost panel research may often be worth even less than what one pays for it. In contrast, users who pay a premium price, deserve more. There is no shame in asking a panel researcher what value-added benefits they provide beyond simply the basic findings their 'generic' competitor offers. This makes sure users get their money's worth. It also pushes that provider to hire better, look deeper and to continue to develop the analytic expertise that will keep them competitive.

The progress in any industry is never linear. This is also true with consumer research. Some techniques and some companies move understanding directly forward, other techniques take marketers on a creative side road, and others make them back-step and rethink progress. But if the widespread decision to select a vendor is based only on speed and cost, the progress in this industry will become dormant.

\section{Rationalisation research and marketing schizophrenia}

There are two dangerous extremes of the research continuum: under-responding to research and over-responding to it. The first leads to rationalisation research; the second leads to marketing schizophrenia.

\section{Rationalisation research}

Consider the danger of under-responding to research. Over US $\$ 6$ bn is spent each year on professional marketing research. A 
sizable amount of this is devoted to justifying, fortifying or rationalising a business decision that has already been made and which now needs to be supported with data. As the cost and speed to ask questions goes down, the temptation to ask more rationalisation-related questions goes up.

When research is so easy to conduct, what keeps it from being commissioned and decommissioned until results fit expectations, and it comes out the way management wants? Under such circumstances, there will be little trouble and little cost to re-commission it, and 'send it back until it is "right"'. In the end, the casualness with which studies are commissioned will be matched by the casualness with which the results are regarded.

\section{Marketing schizophrenia}

The opposite danger is that of over-responding to research findings. Brand managers often look for instantaneous change, and the convenience and affordability of on-line research can nearly instantly satisfy this curiosity. Yet, continuous data may lead to continuous change. Too much change can lead a manager to lose sight of who they are and what their products stand for.

Consider continuous tracking in political polls. Small changes in public opinion create corresponding changes in political strategies. But brands are different. Part of what makes a brand or company valuable is that it stands for consistency in quality and in image. Many of the most powerful brands - Marlboro, Coke, Federal Express - seldom strayed from their image. When brands change their images with the changing of every new brand manager, they leave a confusing or schizophrenic impression in the eyes of consumers.

Just because data are available does not mean they have to be continually accessed and acted upon. 'Stay the course' is, unfortunately, a foreign phrase to many brand managers. The fear of staying the course is often related to the fear of being left behind and becoming a forgotten manager of a forgotten product. While it is good to make midcourse corrections to stay with changes in the winds, there is often a tendency toward overcorrection. Large companies tend to dampen out what might otherwise be a manager's tendency to over-respond to the data. Yet even if a company can save a person from their own best intentions, it is important to acknowledge a tendency to this bias.

The accessibility of continuous online information brings with it the warning to resist making continuous changes that correspond with the continuous change in attitudes. The key is knowing what changes are worth responding to and which are not. That is why 'brand stewards' have a different career trajectory than 'brand administrators.'

\section{Privacy and regulation}

Underlying all of these methods and the techniques for their collection is the ever-present danger that a person's responses can be stolen or abused. ${ }^{4}$ Publicised attacks by hackers on online systems of the CIA, FBI, Microsoft and other organisations have not reduced the public's unease regarding the security of the personal information they give to marketing agencies and websites.

With new developments in personal encryption, the use of personal 'keys' to enter information online and the practice of sending respondent's answers as packets of information instead of a unified whole, the hacker is having a harder time making this type of data meaningful or relating this information back to the respondent. The infinite routes that data travel along the Internet today make even the best 
hackers practically harmless to the research respondent.

While some believe security will be a less sensitive issue in the future, many do not. In the end, the future of panel research rests on the shoulders of consumers. They are one asset with which marketers cannot gamble.

Originally, the Federal Trade Commission (FTC) held a stance of industry self-regulation. Identifying five core principles that they would like the industry to follow was the first step to a structure, or set of guidelines, for federal regulation. ${ }^{5}$ The FTC offers five principles of fair information practices that should be followed:

- notice: communicating how data are collected, the uses of the information, as well as which third parties may receive the information

- choices: giving consumers options as to how any personal information collected from them may be used (opt-in or opt-out)

- access: allowing an individual the ability to access data about themselves and to correct any inaccuracies

- security: taking reasonable steps to ensure the security of information collected

- enforcement: the core principles of privacy protection can only be effective if there is a mechanism in place to enforce them.

Increasing regulation is imminent if companies and the US Congress do not see eye to eye. While it should not be necessary to make new laws regarding this medium, education is vital if marketers and researchers want to continue the relationship and trust of the public that they are so eager to analyse. The ability to 'reach out and touch someone', brings opportunities and responsibilities. While the best intentions can be assumed, these systems must be guarded against the worst.

\section{RECOMMENDATIONS FOR FUTURE CONSUMER PANEL RESEARCHERS}

No competitive advantage lasts for ever, particularly in a service industry. As soon as a new tool is developed, it is only a matter of time before it is replicated and improved by competitors. Nevertheless, the pioneering advantage does have enduring benefits and halos — one of them being financial solvency. The basic theme of this section is that innovative thinking will be one of the biggest assets of the future. Innovative thinking is based on developing the ability to ask and answer 'Why?' and on the ability to envision and develop new products.

\section{Asking and answering 'why?'}

One off-putting but illustrative description of what differentiates insightful researchers from less insightful ones is that insightful researchers are able to 'beat the data until it confesses'. This underscores one way that a number of great researchers have learned to generate insights. It is the iterative three-step process of going from data results to head scratching to data analysis until the picture is clear and the 'why's are answered. Insights from a data set are not found in the first eight sets of cross-tabs conducted. The real value might be in explaining why certain segments differ from others.

'Beat the data until it confesses'. What the data are supposed to confess to is 'why'. For instance, they may be required to confess why:

- people with shopping lists make more impulse purchases

- people buy multiple units of products that are not on special offer 
- restaurant patronage has decreased except for expensive restaurants

- someone who says they 'Buy American' owns a Japanese car

- people buy products they never use

- women like unhealthy 'comfort foods' and men like healthy ones.

Research analysts can become accustomed to analysing data in prespecified, preformatted ways, but this efficiency can also cause them to lose the ability to look more deeply into the meaning behind the results. Many researchers begin to get a flavour for asking 'why' and 'why not' in their graduate training but if their day-to-day responsibilities do not develop this, the skill is lost.

\section{Educating for insights}

It is important to educate analysts to dig deep and look for insightful ways in which to better understand the 'whys' behind the data. There are at least two ways this can be done. One is through theory-based education; the second is through data-driven insights. The first is top-down, the second bottom-up.

\section{Theory-based education}

Theory-based education is built on the belief that the best insights behind how consumers behave can be derived from basic models about how they think. That is, having even a handful of basic models of how consumers make decisions, or how they shop, or why they eat what they do can be used to stimulate questions, insights and analyses that are relevant to a client's basic Monday morning problems.

While theory-based education can be accomplished through high-level graduate courses in psychology, sociology and consumer behaviour, it can also be done through in-house programmes. One common version of this is in the form of 'journal clubs'. Instead of simply 'keeping up with the trade press', the purpose of journal clubs is to push thinking beyond day-to-day needs and to stretch people into thinking outside their comfort level. ${ }^{6}$ This increases practitioners' comfort and skill in asking and answering 'why' questions. One way to encourage this is to try and build process-related models that force researchers to draw arrow and bubble diagrams or flow charts that cause them to think about why consumers behave the way they do.

\section{Data-driven education}

Instead of, or in addition to, using theory-based education to generate insights, data-driven education can also be used. This is more difficult to structure, but can be done in the form of data-driven mysteries. Each week's discussion is led by a different researcher. Their objective is to present a data-related mystery they faced on a prior project and subsequently solved. By walking other researchers through the experience, it provides a case study opportunity to look beyond the numbers and to ask 'why' questions.

This can be in the form of a presentation, but data-driven education appears to be more effective (and more enjoyable to the participants) when it is limited to a minimal number of slides and a good deal of give-and-take discussion. Because the goal of such a process is to put analysts in the shoes of the person leading the discussion, there is a number of ways the discussion can be structured. One way is for the discussion leader to present only the background and importance of the research, then to present the dilemma, and then to open it up for discussion as to how to solve the dilemma. People cannot just casually throw out half thought-out suggestions. 
They must explain their reasoning and the assumptions behind their suggestions. It is important that the whole group be involved in discussion and in converging on the solution. It is only towards the end of the session that the actual results are revealed. After discussing the results, it is productive to ask two questions: 1) Who else has faced a problem similar to this, and how did you solve it? and 2) What are you working on, or have you worked on, where this technique might be useful? Consider the following example.

\section{Example}

Background and importance of research: Knowing what types of measures best predict one's consumption of a packaged good like canned soup, gelatin or cranberry sauce would be useful. These sorts of products are often stockpiled and typical measures of purchase intentions do not capture the true impact of an advert. That is, an advert might stimulate someone to want to eat soup, but they will eat a can from inventory instead of immediately buying a new one. For this reason, it is important to know what type of measure of consumption intention best predicts subsequent consumption.

Data-related dilemma: In designing the panel research, there were two types of consumption measures that were taken for a number of products. These were consumption likelihood questions ('How likely are you to consume canned soup in the next two weeks?' $1=$ unlikely and $9=$ likely) and consumption quantity questions ('How many cans of soup do you think you might consume in the next two weeks?'). A second wave of the panel asked them for the actual consumption of these products along with the three target products the marketers were interested in (soup, gelatin and cranberry sauce). Which measure best predicted actual usage? Herein lies the dilemma. Neither consumption likelihood measures, nor consumption quantity measures correlated with actual usage. The correlation with the first was 0.04 , and -0.07 with the second.

Rationale for possible solutions to the dilemma: In solving this mystery, it is important to understand that these two different measures of usage intent have different relative strengths. With infrequent users of a brand, volume estimates will be skewed toward 0 units (especially over a relatively short period of time). This is partially a drawback of numerical estimates that provide no gradation between 0 and 1 unit. In such cases, volume estimates would provide less variance and less information than an estimate of usage likelihood. As a result, usage likelihood estimates would allow a greater gradation in response and would be more sensitive in detecting any potentially different effects these adverts might have on usage. In contrast, with frequent or heavy users of a brand, a volume estimate is likely to be more accurate than a likelihood estimate. This is because the distribution of these volume estimates is more likely to be normally distributed. As a result, a volume estimate of a person's usage intent is likely to provide more variance and more information about the intended usage of heavy users than is a likelihood measure, which would undoubtedly be at or near 1.0 (100 per cent probable). Under these circumstances, volume estimates would be a more accurate estimate of a heavy user's usage volume of a brand.

Reanalysis of data to test possible explanation: For heavy users, an intended usage volume measure was correlated a respectable 0.60 with actual usage. For light users, a usage likelihood measure was correlated 0.47 with actual usage. ${ }^{7}$ This was much more diagnostic and useful than the aggregated results that were first found. 
This example illustrates a data-driven form of education. It began with an important context in which there was a data dilemma, inconsistency or mystery. Following a discussion - possibly even a series of 'yes' and 'no' questions - a general hypothesised theory about consumers is developed. The last part of the discussion is the outcome of the reanalysis - the solution. The more interactive data-driven sessions are, the more effectively they are burned into the minds of the researchers.

\section{Develop these breakthrough products}

Despite no competitive advantage lasting for ever, innovation is the backbone of most service-related companies. Three areas that are ripe for progress are developing user profiles, determining consumption clusters and preference affiliation and connecting Web browsing with behaviour.

\section{User profile analysis}

When trying to facilitate the adoption of a product or behaviour, it can be useful to know how segments of current users of the product differ psychographically, behaviourally or attitudinally from segments of non-users. Having this information can help identify predisposed segments in order to target them precisely. For instance, knowing the ways in which consumers ('users') of soy products differ from non-users helps to determine more precisely the types of soy-related products that will be most successfully sold to these segments and how these products need to be positioned.

Attempts are also being made to determine the extent to which media preferences - primarily in the form of magazine subscriptions - can provide personality clusters that predict consumption preference across a wide range of products. While it may not be surprising that a person who subscribes to Architectural Digest is more likely to buy a luxury car than a reader of $T V$ Guide, it would be useful to know if other magazines this person subscribes to will help predict the type of luxury car he or she would buy (even before the person themself knows).

\section{Consumption clusters and preference affiliation}

The Internet has brought about an ability to track consumer search patterns and purchase preferences across a wider range of product categories and services than ever before. This volume of data provides a range of possibilities to understand consumers based on the clusters of products they prefer and purchase. These preference affiliations are a target of interest for academics who want to see the extent to which preferences in one category can predict preferences in other categories.

Recent studies of heavy users of consumer packaged goods have examined what personality variables are correlated with heavy usage of a particular brand or category. ${ }^{8}$ By cross-correlating this with heavy usage in other categories, researchers can determine why these particular personality variables drive brand preference and category usage.

\section{Web browsing and purchase predictions}

Many believe that correlating Web-surfing behaviour with long-term behaviour will be the Holy Grail for Web-based researchers and managers. Yet without brilliant, theory-driven analysts, even the most powerful software will yield few surprising insights. The relationship between Web surfing and 
buying behaviour (or preferences) is likely to be either so painfully obvious it is not interesting (eg people who frequently visit fishing-related websites are more likely to buy fishing gear than the average person), or so subtle that the potentially interesting or useful relationships are invisible. If most people were asked how the Web influenced their behaviour as consumers, it is not clear they could even point to direct influences. Perhaps this is because the effects are so ubiquitous they, like the fish in the water, cannot see them. Or perhaps the effects are so subtle that any attempt to try and explain them will be an exercise in futility. The challenge here is knowing what to look for. If marketers do not know what to look for, they are unlikely to find it. Nevertheless, new researchers will be in a better position to correlate Web behaviour with off-line buying behaviour than panel researchers.

\section{SUMMARY}

Indeed, the future for consumer panels is rich. The data collection experience will be rich for consumers, the data will be rich for researchers and hopefully the value will be rich for managers. It is important to remind ourselves that the value a consumer panel has to a manager is partly in the availability of the data, and partly in their usability.

Much of the future of panel data research and the questions that can be answered is limited primarily by creativity and by vision. It is seductive to see the future as technology. What is important to remember is that the greatest assets are the consumers who comprise the panels and those researchers who ask and answer 'Why?'. While the gleam of technology can be mesmerising, it is important to not lose sight of the fact that people - panellists and researchers - will always be the core of what drives the value of panel research.

\section{References}

1 Watson, Thomas, Chairman of IBM, 1943.

2 Attitudes toward products, for instance, are not general. They are specific to products in specific situations. Asking a person's attitude about eating cranberry sauce for Thanksgiving dinner yields a much more positive attitude measure than eating it for a weekday dinner or with chicken.

3 When measuring verbal responses, the general wording for the questions eliciting these responses is 'Please describe in your own words the thoughts and feelings you had when after (seeing this ad for the product, using this brand, comparing these two new package designs, etc.). It is important to understand there are no right or wrong answers. We are interested in the thoughts and feelings you have, so please do not worry about your grammar or about speaking in full sentences.' These directions can also be given in a more guided manner toward specific types of thoughts, and there are pretesting methods that can be used to insure such wording does not bias or guide panellists (see Wansink, B., Ray, M. L. and Batra, R. (1994) 'Increasing cognitive response sensitivity', Journal of Advertising, Vol. 23, No. 2, June, pp. 62-74).

4 Baculski, J. (2001) 'Privacy Issues and Regulations', unpublished working paper, Food and Brand Lab, University of Illinois, Champaign, Il.

5 Gillin, D. (2000) 'The Federal Trade Commission and Internet Privacy', Marketing Research, 12 (Fall), pp. 39-41.

6 A number of companies support Friday afternoon journal clubs. One form these take is a weekly box-lunch affair where one journal article has been pre-assigned for reading and for discussion. In the autumn and in the spring, a group of six-to-ten individuals scans academic journals for articles that might be of interest, and they agree upon one for each week. Articles are scheduled and discussion leaders assigned. The responsibility of each discussion leader is to assign reading-related questions, to direct the discussion and to provide a one-page summary of the insights and implications of the discussion by the following Monday. With some companies, these summaries are distributed through the relevant departments.

7 Wansink, B. and Ray, M. L. (1992) 'Estimating an advertisement's impact on one's consumption of a brand', Journal of Advertising Research, Vol. 26, No. 4, May-June, pp. 9-16.

8 Wansink, B. and Park, S. (2000) 'Accounting for Taste: Prototypes That Predict Preferences', Journal of Database Marketing, Vol. 7, No. 4, pp. 308-320. 